\title{
Sexual experience affects behaviour of bank voles Clethrionomys glareolus
}

\author{
Joanna KAPUSTA, Anna MARCHLEWSKA-KOJ* and Paweł OLEJNICZAK
}

\begin{abstract}
Kapusta J., Marchlewska-Koj A. and Olejniczak P. 1994. Sexual experience affects behaviour of bank voles Clethrionomys glareolus. Acta theriol. 39: 365-371.

Behavioural activity of Clethrionomys glareolus (Schreber, 1780) is modified by social factors. Interaction between sexually nonexperienced (NExp) and experienced (Exp) animals was investigated. Males and females were tested in pairs in the male home cage during $10 \mathrm{~min}$ encounters. Aggressive and nonaggressive behaviour was recorded, and ultrasonic vocalization was monitored by a QMC ultrasound detector. The obtained results indicate that total activity of Exp females was significantly higher than NExp females $(p<0.05)$. Only females exhibited aggressive behaviour toward males, but there was no difference in aggressive activity related to sexual experience. Total activity of Exp males was higher than that of NExp ones $(p<0.05)$. Our previous results indicate that in adult bank voles only males produce ultrasounds. In these experiments significantly more calls was recorded when Exp males were tested and compared with NExp males $(p<0.05)$. This study provides additional information about interaction between breeding and non-breeding animals in a bank vole population.
\end{abstract}

Department of Mammalian Reproduction, Institute of Zoology, Jagiellonian University, ul. Ingardena 6, 30-060 Kraków, Poland (JK, AMK); Department of Hydrobiology, Institute of Environmental Biology, Jagiellonian University, ul. Ingardena 6, 30-060 Kraków, Poland (PO)

Key words: Clethrionomys glareolus, aggression, sexual behaviour, ultrasounds

\section{Introduction}

The natural populations of Clethrionomys glareolus (Schreber, 1780), despite a relatively short breeding season, include females and males differing in sexual experience (Bujalska 1983). As indicated by the results obtained with bank voles in laboratory conditions male and female interactions with conspecifics of the same sex are influenced by male - female interactions. For example, chemosignals released by a male increased interfemale aggression (Marchlewska-Koj et al. 1989). The effect of the presence of a male on female's activity was more pronounced when animals were tested in their home cages than in open field tests. This was observed for both non-aggressive and aggressive behaviour (Jawor and Kruczek 1994).

A considerable body of information exists about the influence of social factors on hormonal activity of bank voles (Hoffmeyer 1982, Kruczek and Marchlewska-

* to whom correspondence should be addressed 
Koj 1986, Kruczek et al. 1989) but very little is known about behavioural interaction between females and males (Clarke 1956). In the experiments that follow we present evidence that sexually naive and sexually experienced $C$. glareolus differ in several aspects of their social behaviour.

\section{Material and methods}

\section{Animals}

The bank voles ( 36 males, 36 females) used in the experiment came from an outbred stock colony reared in the Institute of Zoology, Jagiellonian University in Cracow. The animals were maintained in glass vivaria $\left(40 \times 20 \times 25 \mathrm{~cm}\right.$ ) at $18^{\circ} \pm 2^{\circ} \mathrm{C}$, on a photoperiod schedule of $14 \mathrm{hr}$ light : $10 \mathrm{hr}$ dark (lights on $06.00 \mathrm{hr}$ ). Standard pelleted diet (Rabbit Chow, Motycz, Poland) and water were given ad libitum. Wood shavings were provided as bedding material.

The observations were carried out on 10-15 weeks old, 18-22 g of body weight, sexually experienced and non-experienced males and females randomly allocated to four experimental groups. Sexually non-experienced (NExp) females and males were housed 2-3 per cage. They were reared in groups of the same sex starting from weaning, at 21 days of age.

Monoparous males and females were assumed as sexually experienced (Exp) after first litters had been delivered. On the day of parturition, female and male were separated from their pups and used for behavioural test after next 5-7 days.

\section{Behavioural test}

Tests were performed in the male home cage. A single sexually non-experienced (NExp) or experienced (Exp) male was kept in a vivarium for a week before tested. A naive (NExp) female or monoparous (Exp) female was introduced to a male vivarium and behaviour of each sex was recorded separately. Observations were conducted for 10 min between 11 am and $1 \mathrm{pm}$.

During each test session the total activity was assessed by estimation of non-aggressive and aggressive behaviour. Non-aggressive behaviour was estimated by the latency (in sec) to the first approach and the number of approaches and followings. The number of attacks (boxings and wrestlings) was used as an indicator of aggressive behaviour.

During the test session the ultrasonic vocalizations of animals were recorded using a QMC ultrasound detector type S25 tuned to $20 \mathrm{kHz}$. The microphone was suspended $20 \mathrm{~cm}$ above the floor of the vivarium. Ultrasounds were monitored through headphones for $10 \mathrm{~min}$. The presence or absence of ultrasonic vocalizations during each of the ensuing 120 five-second-blocks of time (10 min total) were recorded (Nyby et al. 1977).

\section{Statistical analysis}

Comparisons between the four experimental groups were made using a two-way analysis of variance (ANOVA). All the counts were transformed according to the formula: $x^{\prime}=\sqrt{x+0.5}$ to make the ANOVA assumptions fulfilled. Comparisons of latencies were performed for females and males separately using Mann-Whitney $U$-test (Sokal and Rohlf 1981).

\section{Results}

Males and females approached each other earlier when an Exp male was present in home cage than with a NExp male (Fig. 1a). This was true during encounters with $\operatorname{Exp}(p<0.01)$ as well as with NExp $(p<0.05)$ females. Although 


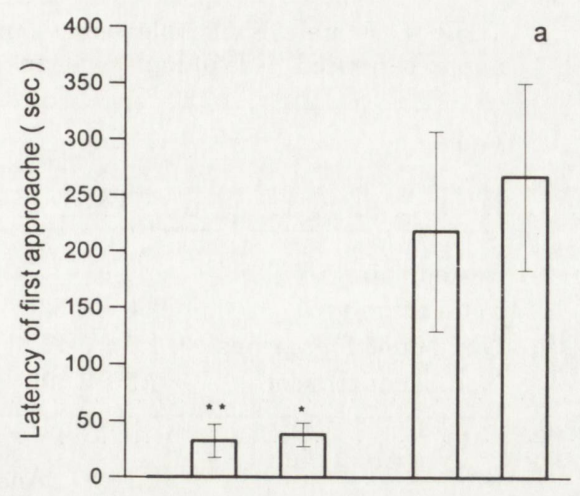

Fig. 1. Behaviour of non-experienced (NExp) or experienced (Exp) males and females tested in pairs during 10 min encounters. (a) Mean $( \pm$ SEM) latency of first approach in pairs. ${ }^{*}-p<0.05,{ }^{* *}-p<0.01$ (Mann-Whitney $U$-test). (b) Mean ( \pm SEM) number of approaches (non-aggressive and aggressive) in pairs. Male: $\mathrm{df}=1,32 ; F 2.221, p=0.145$; female: $\mathrm{df}=1$, $32 ; F 1.414, p=0.243$; interaction: $\mathrm{df}=1,32 ; F 0.242$, $p=0626$ (Two-way ANOVA). $n$ - number of tested pairs.

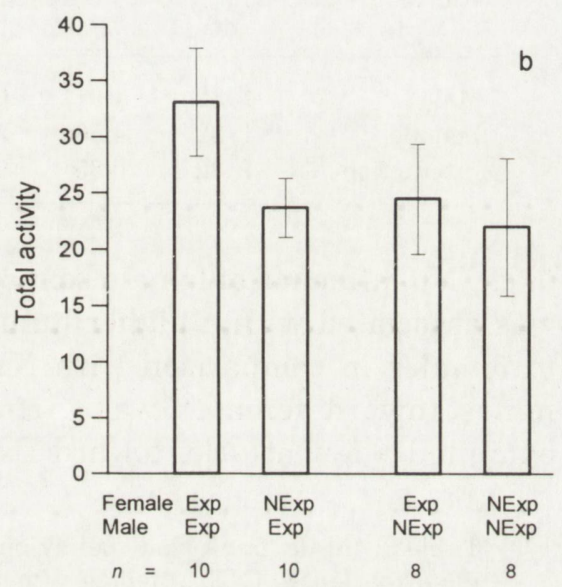

total activities (number of behavioural interactions: approaches, followings and attacks) tended to be higher in pairs with Exp males and Exp females than other pairs, differences were not statistically significant (Fig. 1b).

The total activity in pair also included a number of male and female attacks toward their partners. Aggressive behaviour, estimated as a percentage of attacks of total activity, increased with the presence of sexually experienced female. This was found for pairs of Exp male tested with Exp female 22.0\%, NExp male with Exp female $21.1 \%$, Exp male with NExp female $11.0 \%$ and NExp male with NExp female $10.9 \%$ of total activities.

The behaviour of females and males was analyzed separately. The results concerning female behaviour are summarized in Table 1. Total activity of Exp females was significantly higher than that of NExp females $(p<0.01)$. Exp females attacked males more frequently than NExp females, but differences were not statistically significant.

Also behaviour of bank vole males was affected by their sexual experience (Table 2). The total activity of Exp males was higher than that of NExp one ( $p<$ 
Table 1. Female bank vole behaviour in the presence of sexual experienced (Exp) or non-experienced (NExp) males (mean $\pm \mathrm{SEM})$.

\begin{tabular}{lcccc}
\hline Female & Exp & Exp & NExp & NExp \\
Male & Exp & NExp & Exp & NExp \\
\hline Tested pairs $(n)$ & 10 & 8 & 10 & 8 \\
Total activity & $9.4 \pm 2.33$ & $9.1 \pm 1.51$ & $3.7 \pm 0.98$ & $7.1 \pm 1.66$ \\
Number of approaches & $1.8 \pm 0.47$ & $4.6 \pm 1.21$ & $1.0 \pm 0.42$ & $3.1 \pm 1.14$ \\
Number of attacks & $7.3 \pm 2.10$ & $4.5 \pm 1.90$ & $2.7 \pm 0.70$ & $2.4 \pm 1.00$ \\
\hline
\end{tabular}

Analysis of variance

\begin{tabular}{|c|c|c|c|c|c|c|c|}
\hline \multirow{2}{*}{ Source } & \multirow[b]{2}{*}{ df } & \multicolumn{2}{|c|}{ Total activity } & \multicolumn{2}{|c|}{ Approaches } & \multicolumn{2}{|c|}{ Attacks } \\
\hline & & $F$ & $p$ & $F$ & $p$ & $F$ & $p$ \\
\hline Male & 1,32 & 1.91 & 0.177 & 8.27 & 0.007 & 0.96 & 0.334 \\
\hline Female & 1,32 & 4.66 & 0.038 & 2.62 & 0.115 & 3.32 & 0.078 \\
\hline Interaction & 1,32 & 0.85 & 0.364 & 0.05 & 0.825 & 0.25 & 0.621 \\
\hline
\end{tabular}

0.02). No influence of female sexual experience on male behaviour was found. This was associated with a higher number of non-aggressive approaches of Exp males to females in comparison with NExp males $(p<0.01)$. Aggressive behaviour of males toward females was virtually absent. Only two of eight NExp males exhibited a few attacks toward Exp females (Table 2).

Table 2. Male bank vole behaviour in the presence of sexual experienced (Exp) or non-experienced (NExp) females (mean \pm SEM).

\begin{tabular}{lcccc}
\hline Male & Exp & Exp & NExp & NExp \\
Female & Exp & NExp & Exp & NExp \\
\hline Tested pairs $(n)$ & 10 & 10 & 8 & 8 \\
Total activity & $23.7 \pm 3.09$ & $20.0 \pm 2.31$ & $14.1 \pm 4.46$ & $14.9 \pm 5.29$ \\
Number of approaches & $19.7 \pm 2.88$ & $16.3 \pm 2.17$ & $11.3 \pm 3.73$ & $9.3 \pm 3.26$ \\
Number of attacks & 0.0 & 0.0 & $0.4 \pm 0.18$ & 0.0 \\
\hline
\end{tabular}

Analysis of variance

\begin{tabular}{lcccccc}
\hline \multirow{2}{*}{ Source } & & \multicolumn{2}{c}{ Total activity } & & \multicolumn{2}{c}{ Approaches } \\
\cline { 3 - 4 } \cline { 6 - 7 } & df & $F$ & $p$ & & $F$ & $p$ \\
\hline Male & 1,32 & 6.02 & 0.019 & & 8.62 & 0.006 \\
Female & 1,32 & 0.14 & 0.708 & & 0.47 & 0.496 \\
Interaction & 1,32 & 0.12 & 0.721 & & 0.01 & 0.907 \\
\hline
\end{tabular}




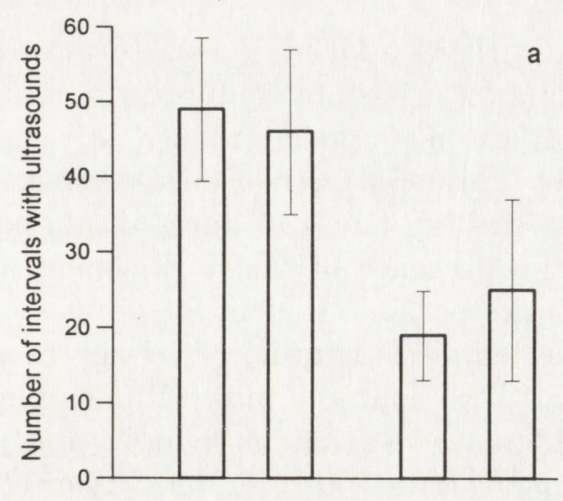

Fig. 2. Ultrasonic vocalization of non-experienced (NExp) and experienced (Exp) males tested in presence of NExp or Exp females during $10 \mathrm{~min}$. (a) Mean \pm SEM number of 5 -sec intervals containing USVs during test. Male: $\mathrm{df}=1,32 ; F 6.555, p<0.02$; female $\mathrm{df}=1,32 ; F 0.015, p=0.905$; interaction $\mathrm{df}$ $=1,32 ; F 0.032, p=0.859$ (Two-way ANOVA). (b) Mean ( \pm SEM) latency of first 5-sec interval with ultrasonic call. ${ }^{*}-p<0.05$ (Mann-Whitney $U$-test). Other dentotations as in Fig. 1.

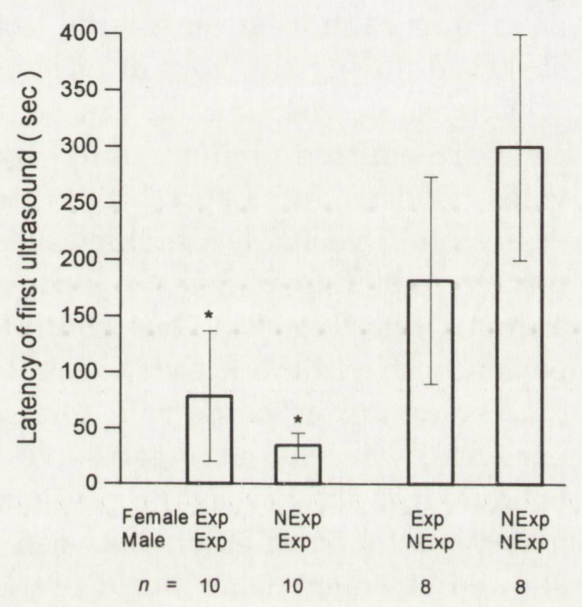

Our previous results indicate that in adult bank voles only males produced ultrasounds on a frequency of about $20 \mathrm{kHz}$ (A. Marchlewska-Koj et al., in press). In the present experiments ultrasounds were recorded in all tested groups (Fig. 2a). There were significantly more calls when Exp males were tested than NExp males but no influence of female sexual experience on vocalizations was found (two-way ANOVA, $p<0.05$ ). As indicated by the latency of the first ultrasonic call (Fig. 2b) the Exp males responded earlier to the presence of females than NExp males did.

\section{Discussion}

As indicated by the results presented above behaviour of bank vole females was different from that of males during 10 min encounters. Females showed aggression toward males. A similar behaviour has been observed in musk shrew Suncus murinus females (Rissman and Bronson 1987). Musk shrew (Rissman et 
al. 1988) and bank vole (Clarke et al. 1970, Jemioło et al. 1980) females are characterized by induced ovulation and lack of typical vaginal estrous cycle. Aggression appears to be a part of sexual activity of females and can be influenced by hormonal activation. In musk shrews, females aggression is well correlated with high levels of adrenal steroids which are required for sexual behaviour in the presence of males (Rissman and Bronson 1987, Fortman et al. 1992). It is quite possible that in $C$. glareolus, similarly to $S$. murinus, reproductive activity of female is stimulated by aggressive behaviour toward males.

The results of many studies performed on rodents revealed a clear pattern of increased sexual motivation and physiological function in sexually experienced males (Hertz et al. 1969, Taylor et al. 1983). We observed increased behavioural activity manifested by high number of approaches and short latency of the first approach of Exp males to female bank voles (Table 2). However, this type of behaviour cannot be considered sexual activity. Mounting or copulation were not observed during the $10 \mathrm{~min}$ encounters.

Ultrasonic vocalization can be a part of courtship in rodents. High frequency calls are emitted predominantly by males. This has been reported for adult pine voles (Cherry and Lepri 1986), prairie voles (Lepri et al. 1988) and bank voles (Sales and Pye 1974, Marchlewska-Koj et al., in press). As indicated by a score of ultrasounds Exp males vocalized more in the presence of females than NExp animals did (Fig. 2). This finding provides additional evidence that sexual experience affects the activity of males.

Aggression of bank vole females was not modified by previous sexual experience, whereas non-aggressive behaviour was. Exp females exhibited higher behavioural activity in the presence of males than NExp females. Females were also able to distinguish between experienced and non-experienced males and showed stronger behavioural preference, expressed by number of approaches, to naive than to Exp males. The ability to distinguish between sexually experienced and non-experienced animals was found also in other rodents. Taylor and co-workers (1989) noticed that male rats exhibited shorter latencies and increased frequency of copulation when they were paired with non-experienced than multiparous females. Higher behavioural activity of monoparous than nulliparous females and males provide additional information about interaction between breeding and non-breeding animals in a bank vole population.

Acknowledgement: The work was supported by grant from the State Committee for Scientific Research, Warsaw, Poland, KBN PB1866 $4 \backslash 91$ to A.M.-K.

\section{References}

Bujalska G. 1983. Sex ratio. [In: Ecology of the bank vole. K. Petrusewicz, ed]. Acta theriol. 28, Suppl. 1: 103-110.

Cherry J. A. and Lepri J. J. 1986. Sexual dimorphism and gonadal control of ultrasonic vocalizations in adult pine voles, Microtus pinetorum. Horm. Behav. 20: 34-48. 
Clarke J. R. 1956. The aggressive behaviour of the vole. Behaviour 9: 1-23.

Clarke J. R., Clulow F. V. and Greig F. 1970. Ovulation in bank vole, Clethrionomys glareolus. J. Reprod. Fertil. 25: 531.

Fortman M., Dellovade T. L. and Rissman E. F. 1992. Adrenal contribution to the induction of sexual behavior in the female musk shrew. Horm. Behav. 26: 76-86.

Hertz Z., Folman Y. and Drori D. 1969. The testosterone content of the testes of mated and unmated rats. J. Endocrinol. 44: 127-128.

Hoffmeyer I. 1982. Responses of female bank voles (Clethrionomys glareolus) to dominant vs subordinate conspecific males. Behav. Neur. Biol. 36: 178-188.

Jawor J. and Kruczek M. 1994. Behaviour of bank vole females during open-field or home-cage tests. Ekol. Pol. (in press).

Jemioło B., Marchlewska-Koj A. and Buchalczyk A. 1980. Acceleration of ovarian follicle maturation of female caused by male in Microtus agrestis and Clethrionomys glareolus. Folia Biol. 28: 269-272.

Kruczek M. and Marchlewska-Koj A. 1986. Puberty delay of bank vole females in a high-density population. Biol. Reprod. 35: 537-541.

Kruczek M., Marchlewska-Koj A. and Drickamer L. C. 1989. Social inhibition of sexual maturation in female and male bank voles (Clethrionomys glareolus). Acta theriol. 34: 479-485.

Lepri J. J., Theodorides M. and Wysocki Ch. J. 1988. Ultrasonic vocalizations by adult prairie voles, Microtus ochrogaster. Experientia 44: 271-273.

Marchlewska-Koj A., Kapusta J., Sales G. D. and Kruczek M. (in press). Ultrasonic calls of bank voles in response to conspecific chemosignals. [In: Chemical signals in vertebrates. R. Apfelbach and D. Muller-Schwarze, eds]. Pergamon Press. Vol. VII.

Marchlewska-Koj A., Kołodziej B. and Filimowska A. 1989. Aggressive behavior of adult bank voles (Clethrionomys glareolus) towards conspecifics. Aggress. Behav. 15: 381-387.

Nyby J., Wysocki Ch. J., Whitney G. and Dizinno G. 1977. Pheromonal regulation of male mouse ultrasonic courtship (Mus musculus). Anim. Behav. 25: 333-341.

Rissman E. F. and Bronson F. H. 1987. Role of the ovary and adrenal gland in the sexual behavior of the musk shrew, Suncus murinus. Biol. Reprod. 36: 664-668.

Rissman E. F., Silveira J. and Bronson F. H. 1988. Patterns of sexual receptivity in the female musk shrew (Suncus murinus). Horm. Behav. 22: 186-193.

Sales G. D. and Pye J. D. 1974. Ultrasonic communication by animals. Chapman and Hall, London: 149-201

Sokal R. R. and Rohlf F. J. 1981. Biometry: the principles and practice of statistics in biological research. Freeman, San Francisco: 321-344, 423-436.

Taylor G. T., Regan D. and Haller J. 1983. Sexual experience, androgens and female choice of a mate in laboratory rats. J. Endocrinal. 96: 43-52.

Taylor G. T., Bardgett M., Griffin M. and Weiss J. 1989. Reproductive behavior and physiology of nulliparous female rats after sexual experience. Behav. Proc. 19: 31-46.

Received 9 June 1994, accepted 12 September 1994. 